Received 00th January 20xx, Accepted 00th January 20xx DOI: $10.1039 / x 0 x \times 00000 x$

\title{
Determination of acidity constants at 37 ㅇ through the internal standard capillary electrophoresis (IS-CE) method: internal standards and application to polyprotic drugs
}

\author{
Leo Lebanov ${ }^{a}$, Elisabet Fuguet ${ }^{\mathrm{a}, \mathrm{b}}$, Javier M. Melo ${ }^{\mathrm{a}}$ and Martí Rosés *a
}

\begin{abstract}
This work provides the $\mathrm{pK}_{\mathrm{a}}$ at the biorelevant temperature of $37 \stackrel{\mathrm{O}}{\mathrm{C}}$ for a set of compounds proposed as internal standards for the internal standard capillary electrophoresis (IS-CE) method. This is a high throughput method that allows the determination of the acidity constants of compounds in a short time, avoiding the exact measurement of the pH of the buffers used. $\mathrm{pH}$ electrode calibration at $37 \stackrel{\circ}{\circ} \mathrm{Can}$ be avoided too.
\end{abstract}

\begin{abstract}
In order to anchor the $\mathrm{pK}_{\mathrm{a}}$ values obtained through the IS-CE method in the $\mathrm{pH}$ scale, the acidity constant at 37 으 of some of the standards has been determined also by the reference potentiometric method. In general, a decrease in the $\mathrm{pK}_{\mathrm{a}}$ value is observed when changing from 25 to $37 \stackrel{\circ}{\circ}$, and the magnitude of the change depends on the nature of the compounds.
\end{abstract}

Once the $\mathrm{pK}_{\mathrm{a}}$ values at $37 \stackrel{\mathrm{C}}{\mathrm{C}}$ of the internal standards have been established, the method is applied to the determination of the acidity constants of seven polyprotic ( 5 diprotic and 2 triprotic) drugs. The obtained mobility-pH profiles show well defined curves, and the fits provide precise $\mathrm{pK}_{\mathrm{a}}$ values. Due to the lack of reference data at $37 \stackrel{\mathrm{C}}{\mathrm{C}}$ only the $\mathrm{pK}_{\mathrm{a}} \mathrm{s}$ of labetalol can be compared to values from literature, and a very good agreement is observed.

\section{Introduction}

In the past decades, pharmaceutical industry has undergone considerable changes due to application of many cutting-edge technologies such as combinatorial chemistry, high throughput screening, and robotics, and all these new technologies have lead to the possibility to synthetize millions of compounds for a high number of different health conditions and diseases. The drug discovery process is very complex, expensive, and timeconsuming; in average, it takes from 10 to 15 years from the discovery of a new compound until the new drug is released to the market. The development of better screening methods for the evaluation of physicochemical properties of candidate compounds at the early stage of the drug discovery process can reduce time, decrease expenses, and diminish the number of failures in the late stage of drug development. Therefore, there is a great need for high-throughput screening methods for a rapid determination of physicochemical properties of candidate drug compounds. ${ }^{1-3}$

One of the properties that affects the pharmaceutical potential of a compound, among others, is the acidity constant. The acidity constant determines the degree of ionization of the compound, which has impact on its solubility, dissolution rate,

\footnotetext{
a. Departament d'Enginyeria Química i Química Analítica and Institut de Biomedicina (IBUB). Universitat de Barcelona. Martíl Franquès 1-11, 08028 , Barcelona, Spain.

b. Serra Húnter Programme, Generalitat de Catalunya, Spain.

Electronic Supplementary Information (ESI) available: [details of any supplementary information available should be included here]. See DOI: 10.1039/x0xx00000x
}

absorption across biological membranes (lipophilicity and permeability), distribution to the site of action, renal elimination, interaction with efflux systems, metabolism, protein binding, and receptor interactions. ${ }^{2,4-5}$ Nonetheless, most of the acidity constants are determined at $25^{\circ} \mathrm{C}$ or at room temperature, which usually can range from 15 to $30^{\circ} \mathrm{C}$, instead of at 37 으, the common human biorelevant temperature. Accurate determinations of the $\mathrm{pK}_{\mathrm{a}}$ values at 37 ${ }^{\circ} \mathrm{C}$ is important for all drugs introduced orally, intramuscularly or any other way in which candidate compound should be absorbed, distributed, metabolized or excreted at the normal body temperature. Acidity constant, $\mathrm{pK}_{\mathrm{a}}$ in its logarithmic form, depends on temperature $(T)$, and many studies demonstrate that change of $\mathrm{pK}_{\mathrm{a}}$ value due to temperature depends on the nature of the functional groups of the compounds. Whereas simple carboxylic acids have nearly the same $\mathrm{pK}_{\mathrm{a}}$ value at 25 and $37{ }^{\circ} \mathrm{C}$, the $\mathrm{pK}_{\mathrm{a}}$ values of some bases or phenols show an important temperature dependence. ${ }^{5-10}$ For example, quetiapine, a basic anti-psychotic drug, with $\mathrm{pK}_{\mathrm{a} 1}$ $=2.27$ and $\mathrm{pK}_{\mathrm{a} 2}=7.30$ at $25{ }^{\circ} \mathrm{C}^{11}$ changes its $\mathrm{pK}_{\mathrm{a}}$ values to 3.56 and 6.38 at $37{ }^{\circ} \mathrm{C}^{5}$, respectively. Although the variation of the second $\mathrm{pK}_{\mathrm{a}}$ is not as big as for the first $\mathrm{pK}_{\mathrm{a}}$ value, its proximity to the physiological $\mathrm{pH}$ of 7.4 makes accurate determination of $\mathrm{pK}_{\mathrm{a}}$ value even more important. Thus, the ionization degree of quetiapine at physiological conditions of $\mathrm{pH}$ will be lower at $37{ }^{\circ} \mathrm{C}$ than at $25 \stackrel{\circ}{ } \mathrm{C}$, fact that can lead to wrong biodisponibility conclusions if the considered $\mathrm{pK}_{\mathrm{a}}$ values are the ones at $25^{\circ} \mathrm{C}$.

This work is focused on the use of the internal standard capillary electrophoresis method (IS-CE) for the determination 
of $\mathrm{pK}_{\mathrm{a}}$ values at $37 \mathrm{\circ}$. CE has several advantages compared to other methods for the determination of acidity constants. It is a highly automated technique that requires small amounts of compounds and where high purity is not required due to the separation performed inside the capillary. ${ }^{12-19}$ The IS-CE method is based on the use of an internal standard (i.e. a compound with known $\mathrm{pK}_{\mathrm{a}}$ ) to measure the $\mathrm{pH}$ inside the capillary. This is obtained from the $\mathrm{pK}_{\mathrm{a}}$ value of the IS and the ratio of mobilities of the pure ionic form of the IS, and the mobility at a $\mathrm{pH}$ where it is partially ionized. Once the $\mathrm{pH}$ is known, the ratio of mobilities of the test compound (fully and partially ionized) is used to determine its $\mathrm{pK}_{\mathrm{a}} \mathrm{e}^{20,21}$ Compared to the classical CE method for determination of acidity constants, the IS-CE is much faster, and it does not require a previous exact measurement of the $\mathrm{pH}$ value of the buffer, since the $\mathrm{pH}$ is measured in situ in the capillary under the exact conditions of analysis. This is especially relevant in measurements at a given temperature, since the calibration of the electrodic system used to measure the $\mathrm{pH}$ of the buffers at the working temperature can be avoided. Moreover, previous works have demonstrated that if the IS and the analyte behave in a similar way, possible alterations in the experimental conditions that may affect the mobilities of the test compound (as for example Joule effect) can be compensated by the IS.6,22 On the contrary, in the classical CE method any alteration of the mobility of the analyte leads to a direct error in the $\mathrm{pK}_{\mathrm{a}}$ determination. ${ }^{14}$

The IS-CE method has been well established for the determination of $\mathrm{pK}_{\mathrm{a}}$ values of all types of acid-base compounds at $25 \circ$. . Nevertheless, there is a lack of $\mathrm{pK}_{\mathrm{a}}$ values for internal standards at $37 \stackrel{\circ}{ } \mathrm{C}$. The main purpose of this work is, therefore, to establish the $\mathrm{pK}_{\mathrm{a}}$ values at $37 \stackrel{\circ}{ } \mathrm{C}$ for a reference set of internal standards in order to make this highthroughput method applicable to the characterization of drugs at the human biorelevant temperature.

\section{Theory}

For an ionizable acid-base compound, the electrophoretic mobility depends on the degree (or degrees) of ionization of the compound. Thus, the general acid-base equilibria for a monoprotic species, $\mathrm{HX}^{\mathrm{z}}$, can be expressed as:

$$
H X^{2} \rightleftarrows \mathrm{X}^{\mathrm{z}-1}+\mathrm{H}^{+} \quad \mathbf{p K _ { \mathbf { a } } ^ { \prime }}=\mathbf{p H}-\log \frac{\left[\mathrm{x}^{\mathrm{z}-1}\right]}{\left[\mathrm{HX}^{2}\right]}
$$

where $z$ is the charge number of the protonated species and $\mathrm{pK}_{\mathrm{a}}{ }^{\prime}$ the logarithmic form of the mixed acidity constant (at a given ionic strength, as well as temperature and solvent)..$^{23,24}$

The $\mu_{\mathrm{ep}}$, also called the effective mobility $\left(\mu_{\mathrm{eff}}\right)$, of a monoprotic compound can be expressed as a function of the $\mathrm{pK}_{\mathrm{a}}{ }^{\prime}$ of the species and the $\mathrm{pH}$ of the background electrolyte through the following general equation ${ }^{13}$ :

$\boldsymbol{\mu}_{\mathrm{eff}}=\frac{\mu_{\mathrm{HX}^{\mathrm{z}}}+\left(\mu_{\mathrm{x}^{\mathrm{z}}-\mathbf{1}}\right) 10^{\mathrm{pH}-\mathrm{pK}_{\mathrm{a}}^{\prime}}}{1+10^{\mathrm{pH}-\mathrm{pK}_{\mathrm{a}}^{\prime}}}$ where $\mu_{\mathrm{HX}^{\mathrm{z}}}$ and $\boldsymbol{\mu}_{\mathrm{X}^{\mathrm{z}-1}-1}$ are the actual ionic electrophoretic mobilities of the subscripted species.

In the IS-CE method, the use of an IS allows direct calculation of the $\mathrm{pH}$ of the buffered solution inside the capillary. This value is then used to calculate $\mathrm{pK}_{\mathrm{a}}{ }^{\prime}$ of the compound being studied.

For example, for a neutral acid used as the IS, where $\mathrm{z}$ is 0 , the $\mathrm{pH}$ value can be given, by rearranging Eq. 2 , by:

$\mathbf{p H}=\mathbf{p K} K_{\mathbf{a}(\mathrm{IS})}^{\prime}-\log \frac{\mu_{\mathrm{IS}^{-}}-\mu_{\text {eff(IS) }}}{\mu_{\text {eff(IS) }}}$

where $\boldsymbol{\mu}_{\text {eff(IS) }}$ is the effective mobility and $\boldsymbol{\mu}_{\mathrm{IS}}$-the actual ionic mobility (mobility of the fully charged negative species) of the IS. The term corresponding to the uncharged species, $\boldsymbol{\mu}_{\mathrm{HX}}$, has zero mobility and is removed from Eq 2 . Since $\mathbf{p K}_{\mathbf{a}(\mathbf{I S})}^{\prime}$ of the IS is well known, only two runs at two different $\mathrm{pH}$ values are needed to calculate the $\mathrm{pH}$ : the first where the $\mathrm{pH}$ is in the range $\mathrm{pK}_{\mathrm{a}} \pm 1$, in order to calculate the effective mobility; and a second in which it is completely ionized to calculate the actual ionic mobility. Therefore, although a buffer could experiment $\mathrm{pK}_{\mathrm{a}}$ shifts due to temperature, the provided $\mathrm{pH}$ inside the capillary can be known by the relation of mobilities and $\mathrm{pK}_{\mathrm{a}}$ of the IS.

Once the $\mathrm{pH}$ inside the capillary is known, the acidity constant of the test compound (TC) can be calculated by rearranging Eq. 2 again:

$\mathbf{p K ^ { \prime } ( \mathrm { TC } )}=\mathbf{p H}-\log \frac{\mu_{\mathrm{HX}}-\mu_{\mathrm{eff}(\mathrm{TC})}}{\mu_{\mathrm{eff}(\mathrm{TC})}-\mu_{\mathrm{x}^{\mathrm{z}}-1}}$

where $\boldsymbol{\mu}_{\mathrm{HX}^{\mathrm{z}}}$ and $\boldsymbol{\mu}_{\mathrm{X}^{\mathrm{z}-1}}$ refer to the actual ionic mobilities of the fully charged $z$ and $z-1$ species of the TC.

In these equations, $\mathbf{p} \mathbf{K}_{\mathbf{a}(\mathbf{T C})}^{\prime}$ is related to the thermodynamic $\mathrm{pK}_{\mathrm{a}}$ by the activity coefficients, usually calculated by means of the Debye-Hückel equation (Eq. 5) ${ }^{21}$ :

$$
-\log \gamma=\frac{A z^{2} \sqrt{I}}{1+B a \sqrt{I}}
$$

$I$ is the ionic strength of the buffer solutions $(0.05 \mathrm{M}$ in this work), $A$ and $B$ depend on the solvent relative permittivity and temperature (their values are 0.523 and 0.331 , respectively, in water at $37 \circ \mathrm{O}), \mathrm{z}$ is the charge number of the ion, and $\mathrm{a}$ is the hydrated radius of the ion. The value of a depends on the hydrated ion, although a value of $4.5 \AA$ (value for hydrogen ion) is commonly taken for most ions. This equation is valid for ionic strength values lower than $0.2 \mathrm{M}$. Activity coefficients of neutral species $(z=0)$ are assumed to be unity.

In case of polyprotic compounds, equation 2 becomes equation 6: 
$\mu_{e f f}=\frac{\mu_{H_{n} X^{z}}+\sum_{i=1}^{n} 10^{i p H-\sum_{j=1}^{i} p K_{a j}^{\prime}}{ }_{\mu_{H_{n-i} X^{z-i}}}}{1+\sum_{i=1}^{n} 10^{i p H-\sum_{j=1}^{i} p^{\prime \prime K_{a j}}}}$

This is a general expression that relates effective mobility and $\mathrm{pH}$ for any type of acid-base compound.

Electrophoretic mobility values are calculated through the migration times of the analyte $\left(t_{m}\right)$ and the electroosmotic flow marker $\left(t_{0}\right)$ according to equation 7 :

$\mu_{\text {ep }}=\frac{L_{T} L_{D}}{V}\left(\frac{1}{t_{\mathrm{m}}}-\frac{1}{t_{0}}\right)$

where $L_{T}$ and $L_{D}$ are the total and effective capillary length, respectively, and $V$ is the applied voltage. Mobilities obtained in this way can be directly used only in absence of Joule heating effect, which causes an increase of temperature inside the capillary above the temperature of the capillary coolant. Otherwise, temperature corrections of measured mobilities must be applied. 25,26

\section{Experimental}

\section{Apparatus and conditions.}

CE determinations were performed in a P/ACE MDQ Beckman instrument (Palo Alto, CA, USA) equipped with a diode-array spectrophotometric detector. A fused-silica capillary of $50 \mu \mathrm{m}$ i.d. and $375 \mu \mathrm{m}$ o.d. from Polymicro Technologies (Phoenix, AZ, USA) was used. Capillary had a total length of $35.2 \mathrm{~cm}$, and an effective length of $25.0 \mathrm{~cm}$. Samples were injected at a hydrodynamic pressure of $2068 \mathrm{~Pa}$ (0.3 p.s.i.) during $2.0 \mathrm{~s}$. Separation was performed applying a pressure of $3447 \mathrm{~Pa}(0.5$ p.s.i.) and a voltage of $20 \mathrm{kV}$. The absence of Joule effect at these separation conditions has been tested for each of the used buffers, by checking the linearity between the applied voltage and the generated current according Ohm's law. Detection was carried out at 214, 254 and $280 \mathrm{~nm}$ with full spectra captured from 190 until 300nm. Capillary together with sample tray were thermostated at $37^{\circ} \mathrm{C}( \pm 0.1 \stackrel{\circ}{\circ})$. Under these conditions electrophoretic runs duration was under 5 minutes in most of the buffers.

Potentiometric $\mathrm{pK}_{\mathrm{a}}$ determinations were performed in an 888 Titrando potentiometer from Metrohm (Herisau, Switzerland), equipped with a combined $\mathrm{pH}$ electrode and a burette also from Metrohm, a tempering beaker, and a temperaturecontrolled water bath (J. P. Selecta, Abrera, Spain).

\section{Reagents and materials.}

Sodium hydroxide (0.5M TitrisolTM) and hydrochloric acid (1M TitrisolTM), dimethyl sulfoxide ( $>99.8 \%)$, and sodium dihydrogen phosphate monohydrate (>99\%) were from Merck (Darmstadt, Germany). Methanol (HPLC grade) was from Thermo Fischer Scientific (Waltham, MA, USA). Sodium acetate anhydrous (>99.6\%) was from Baker (Center Valley, PA, USA).
Potassium hydrogen phthalate $(>99.9 \%)$, BisTris $(2,2-$ Bis(hydroxymethyl)-2,2',2"-nitrilotriethanol) (>99\%), Tris (Tris(hydroxymethyl) aminomethane) (>99.9\%), CHES (2(cyclohexylamino)ethanesulfonic acid) (>99\%), and CAPS (3(cyclohexylamino)-1-propanesulfonic acid) (>98\%) were from Sigma-Aldrich (St Louis, MO, USA). Water was purified by a Milli-Q plus system from Millipore (Bedford, MA, USA), with a resistivity of $18.2 \mathrm{M} \Omega \mathrm{cm}$.

All internal standards and drugs used for the determinations were obtained from Sigma-Aldrich, Scharlab (Sentmenat, Spain), Merck, Panreac (Castellar del Vallès, Spain), Carlo Erba (Milano, Italy), and J. T. Baker with purity above $98 \%$.

\section{Procedures.}

CE capillary conditioning. Capillary conditioning methodology was reported previously. ${ }^{21}$ Briefly, before the first use it was conditioned with $1 \mathrm{M} \mathrm{NaOH}$, water and the running buffer; when the buffer was changed it was rinsed with water and the new buffer; and between runs it was rinsed for 3 minutes with the running buffer. At the end of the working session the capillary was flushed with water.

\section{Preparation of buffers and solutes for CE analysis. Buffer} solutions covering practically all the useful $\mathrm{pH}$ range (from 2.0 to 12.0 separated at intervals of $0.5 \mathrm{pH}$ units) were prepared at the approximate $\mathrm{pH}$ and $50 \mathrm{mM}$ ionic strength as described elsewhere. ${ }^{21}$

Stock solutions of test compounds and ISs were prepared at a concentration of $1 \mathrm{mg} \mathrm{mL}^{-1}$ and $2 \% \mathrm{v} / \mathrm{v}$ of DMSO was added as electroosmotic flow (EOF) marker. They were diluted in water or in a methanol/water mixture (when they were not soluble in water itself). Afterwards, a 1/10 dilution of the stock solution in water was prepared for injection (100 $\mathrm{mg} \mathrm{L}^{-1}, 0.2 \%$ v/v DMSO). Internal standards and test compounds were stored at $4 \stackrel{\circ}{ } \mathrm{C}$ until used. All the samples and buffers were filtered through a nylon mesh $0.45 \mu \mathrm{m}$ porous size (Whatman, Maidstone, UK).

Potentiometric determination of $\mathrm{pK}_{\mathrm{a}}$ values. $30 \mathrm{~mL}$ of an approximately $0.005 \mathrm{M}$ aqueous solution of the IS were placed in the thermostated beaker for the titration. Once the solution had reached $37 \stackrel{\circ}{\circ}$, the titration was performed using $0.1 \mathrm{M}$ sodium hydroxide or $0.1 \mathrm{M}$ hydrochloric acid, depending on the nature of the IS from $\mathrm{pH} 2$ to $\mathrm{pH} 12$, or vice versa. All solutions (titrands and titrants) were prepared with boiled water. $0.1 \mathrm{M}$ sodium hydroxide solution was previously standardized with potassium hydrogen phthalate. $0.1 \mathrm{M}$ hydrochloric acid solution was standardized using Tris as primary standard. The potentiometric system was calibrated with standard reference solutions at $\mathrm{pH} 2,4,7$, and 9 at 37 으. $\mathrm{pK}_{\mathrm{a}}$ was calculated through the titration data, taking into account the mass and charge balances of the species in equilibrium. Activity corrections at each titration point were 
done through the activity coefficients, which were calculated through the Debye-Hückel equation.

\section{Data analysis.}

Table Curve 2D from Systat Software Inc. (San Jose, CA, USA) was used to fit the mobility - $\mathrm{pH}$ curves of polyprotic drugs. Other data calculations were performed through Excel 2010 from Microsoft (Redmond, WA, USA).

\section{Results and discussion}

Determination of the $\mathrm{pK}_{\mathrm{a}}$ at $37 \mathrm{O} \mathrm{C}$ for the set of internal standards.

In order to establish IS-CE as a high-throughput method for determination of $\mathrm{pK}_{\mathrm{a}}$ values at $37^{\circ} \mathrm{C}$ it is necessary to precisely determine $\mathrm{pK}_{\mathrm{a}}$ values of internal standards at this temperature. For this purpose, the previously established set of 23 monoprotic acids and 22 monoprotic bases ${ }^{22,27}$ has been used. These compounds have different chemical properties and cover the most useful $\mathrm{pH}$ range in CE. Table 1 lists the set

Table $1 \mathrm{pK}_{\mathrm{a}}$ values for the set of internal standards. Standard deviations are shown in parentheses.

\begin{tabular}{|c|c|c|c|c|}
\hline Internal Standards & $\mathrm{pK}_{\mathrm{a}} 25 \mathrm{o}^{22,27}$ & $\mathrm{~N}$ & Reference $\mathrm{pK}_{\mathrm{a}} 37^{\circ} \mathrm{O} \mathrm{C}$ & IS-CE $\mathrm{pK}_{\mathrm{a}} 37^{\circ} \mathrm{OC}$ \\
\hline 2-Chlorobenzoic acid (A) & $2.84(0.02)$ & 6 & & $2.79(0.01)$ \\
\hline 2,6-Dibromo-4-nitrophenol (A) & $3.31(0.03)$ & 7 & & $3.24(0.03)$ \\
\hline 4-Nitrobenzoic acid (A) & $3.37(0.01)$ & 7 & $3.44^{28}$ & $3.27(0.04)$ \\
\hline 2,6-Dinitrophenol $(A)$ & $3.69(0.01)$ & 7 & & $3.57(0.04)$ \\
\hline 3-Bromobenzoic acid (A) & $3.79(0.02)$ & 6 & & $3.71(0.05)$ \\
\hline 2,4-Dinitrophenol (A) & $4.12(0.02)$ & 8 & & $3.89(0.07)$ \\
\hline Benzoic acid $(A)$ & $4.22(0.03)$ & 18 & $4.24^{5}$ & $4.07(0.07)$ \\
\hline Ibuprofen (A) & $4.49(0.02)$ & 24 & $4.51^{29}$ & $4.37(0.06)$ \\
\hline Aniline (B) & $4.63(0.02)$ & 14 & $4.41(0.03)$ & $4.53(0.05)$ \\
\hline 4-tert-Butylaniline (B) & $4.93(0.01)$ & 22 & & $4.56(0.07)$ \\
\hline Quinoline (B) & $4.93(0.01)$ & 14 & $4.73(0.02)$ & $4.86(0.03)$ \\
\hline Warfarin (A) & $5.17(0.04)$ & 11 & & $4.79(0.06)$ \\
\hline$N, N$-Dimethyl- $N$-phenylamine (B) & $5.17(0.02)$ & 6 & & $5.32(0.12)$ \\
\hline Pyridine (B) & $5.28(0.01)$ & 7 & $5.09^{30}$ & $5.14(0.04)$ \\
\hline 2,5-Dinitrophenol (A) & $5.30(0.05)$ & 11 & & $5.05(0.06)$ \\
\hline Sulfacetamide (B) & $5.42(0.05)$ & 14 & & $5.25(0.05)$ \\
\hline Acridine (B) & $5.55(0.06)$ & 9 & $5.01^{31}$ & $5.37(0.07)$ \\
\hline 4-tert-Butylpyridine (B) & $6.03(0.03)$ & 13 & & $5.92(0.06)$ \\
\hline 2,4,6-Tribromophenol (A) & $6.04(0.08)$ & 13 & & $5.88(0.05)$ \\
\hline Papaverine (B) & $6.41(0.07)$ & 8 & $6.22^{32}$ & $6.32(0.04)$ \\
\hline 2,4-Lutidine (B) & $6.81(0.05)$ & 19 & & $6.66(0.06)$ \\
\hline Trazodone (B) & $6.84(0.05)$ & 11 & & $6.69(0.04)$ \\
\hline Pilocarpine (B) & $7.08(0.02)$ & 12 & $6.68(0.01)$ & $6.85(0.03)$ \\
\hline 4-Nitrophenol (A) & $7.09(0.05)$ & 16 & $7.08(0.01)$ & $6.82(0.06)$ \\
\hline Vanillin (A) & $7.36(0.06)$ & 21 & & $7.16(0.05)$ \\
\hline 2,4,6-Trimethylpyridine (B) & $7.51(0.03)$ & 10 & $7.16(0.02)$ & $7.22(0.07)$ \\
\hline Phenobarbital (A) & $7.53(0.04)$ & 22 & & $7.17(0.05)$ \\
\hline 4-Hydroxybenzaldehyde (A) & $7.61(0.04)$ & 10 & & $7.35(0.05)$ \\
\hline Lidocaine (B) & $7.93(0.01)$ & 14 & $7.56(0.01)$ & $7.78(0.05)$ \\
\hline 3,5-Dichlorophenol (A) & $8.18(0.04)$ & 11 & $8.11(0.01)$ & $7.92(0.05)$ \\
\hline Bupivacaine (B) & $8.19(0.03)$ & 10 & $7.97^{33}$ & $7.96(0.07)$ \\
\hline Methylparaben (A) & $8.35(0.03)$ & 16 & $8.21(0.01)$ & $8.14(0.06)$ \\
\hline 2-Chlorophenol (A) & $8.50(0.04)$ & 15 & & $8.22(0.06)$ \\
\hline
\end{tabular}




\begin{tabular}{lllll} 
1-Phenylpiperazine (B) & $8.75(0.02)$ & 9 & $8.33(0.02)$ & $8.41(0.07)$ \\
N,N-dimethyl-N-benzylamine (B) & $8.95(0.04)$ & 11 & $8.64(0.04)$ & $8.76(0.05)$ \\
3-Chlorophenol (A) & $9.04(0.01)$ & 16 & & $8.73(0.06)$ \\
Diphenhydramine (B) & $9.08(0.02)$ & 15 & $8.85^{5}$ & $8.83(0.06)$ \\
4-Bromophenol (A) & $9.28(0.01)$ & 27 & & $9.01(0.05)$ \\
Imipramine (B) & $9.37(0.02)$ & 17 & $9.23^{34}$ & $9.25(0.05)$ \\
Propranolol (B) & $9.47(0.00)$ & 23 & $9.17^{32}$ & $9.24(0.08)$ \\
1-Aminoethylbenzene (B) & $9.52(0.01)$ & 11 & & $9.34(0.10)$ \\
Paracetamol (A) & $9.58(0.02)$ & 11 & $9.65^{35}$ & $9.31(0.03)$ \\
Ephedrine (B) & $9.72(0.02)$ & 12 & $9.12(0.01)$ & $9.27(0.04)$ \\
Phenol (A) & $9.89(0.01)$ & 13 & $9.83(0.01)$ & $9.54(0.06)$ \\
Nortriptyline (B) & $10.08(0.01)$ & 5 & & $9.79(0.04)$ \\
\hline
\end{tabular}

of internal standards, together with their thermodynamic $\mathrm{pK}_{\mathrm{a}}$ values at $25 \stackrel{\circ}{ }$ C.

A similar approach as the one used at $25 \circ \mathrm{C}$ has been applied to determine the new $\mathrm{pK}_{\mathrm{a}}$ values. ${ }^{22,27}$ Compounds with $\mathrm{pK}_{\mathrm{a}}$ values differing less than one unit have been paired, and the roles of test compound and internal standard assigned. For this initial experimental design, $\mathrm{pK}_{\mathrm{a}}$ values at $25 \stackrel{\circ}{\mathrm{C}}$ have been used when reference data at 37 ㅇ C (Reference $\mathrm{pK}_{\mathrm{a}} 37 \mathrm{\circ} \mathrm{C}$ in Table 1) are not available. Then, each pair has been injected twice in the system at $37^{\circ} \mathrm{C}$. Firstly, using a buffer at a $\mathrm{pH}$ value where both compounds are partially ionized to obtain the effective mobilities. Secondly, in a buffer at a $\mathrm{pH}$ value where they are totally ionized, to obtain the actual ionic mobilities. In case of pairs of different acid-base nature, actual ionic mobilities have been obtained at two $\mathrm{pH}$ values (2.0 for acids and 12.0 for bases). In several instances the same pair has been injected at different $\mathrm{pH}$ values for the effective mobility determination, which rises the number of independent experiments $(N)$ for each compound.

Once mobilities are calculated, Eq. 4 has been applied to each pair. To calculate the $\mathrm{pK}_{\mathrm{a}}$ of the test compound, obtained mobility data and the $\mathrm{pK}_{\mathrm{a}}$ at 25 으 (or at 37 ㅇ $\mathrm{C}$ when possible) of the compound used as internal standard have been used. In this way, $\mathrm{N}$ new $\mathrm{pK}_{\mathrm{a}}$ values have been obtained for a given compound of the set. The average of these $\mathrm{N} \mathrm{pK_{a }}$ s provides a new value to start the iterative process, in which the same electrophoretic data is used, but the $\mathrm{pK}_{\mathrm{a}} \mathrm{s}$ of the ISs are changed by the averaged values. The process has been repeated four times, until the differences between consecutive averaged $\mathrm{pK}_{\mathrm{a}} \mathrm{s}$ has been $0.02 \mathrm{pK}_{\mathrm{a}}$ units or less. Once the iteration process has finished, boxplots have been used to identify possible outliers within the $\mathrm{N} \mathrm{pK}_{\mathrm{a}}$ values obtained for a same compound. Tukey's criterium has been used to remove the outliers.

Next step is to anchor the $\mathrm{pK}_{\mathrm{a}}$ scale by comparison of the obtained $\mathrm{pK}_{\mathrm{a}}$ values to the known reference values. As accurate literature $\mathrm{pK}_{\mathrm{a}}$ data at $37 \stackrel{\circ}{\mathrm{O}} \mathrm{C}$ was scarce for the set of compounds used in this work, potentiometric determinations at $37^{\circ} \mathrm{C}$ have been performed for some of the compounds in order to widen the available reference data. A linear trend is observed when the raw CE data is compared to the potentiometric data, according to Eq. 8:

$\mathrm{pK}_{\mathrm{a}, \mathrm{IS}-\mathrm{CE}, \text { raw }}=0.165(0.140)+0.986(0.019) \mathrm{pK}_{\mathrm{a}, \text { Ref }}$

$\mathrm{n}=21 ; \mathrm{SD}=0.170 ; \mathrm{F}=2925$

here $\mathrm{pK}_{\mathrm{a}, \mathrm{IS}-\mathrm{CE} \text { raw }}$ is the $\mathrm{pK}_{\mathrm{a}}$ obtained through the electrophoretic method just after the refinement process, $\mathrm{pK}_{\mathrm{a}}$, Ref is the $\mathrm{pK}_{\mathrm{a}}$ determined potentiometrically or obtained from the literature, $\mathrm{n}$ is the number of compounds used for the correlation, SD is the standard deviation of the correlation, and $F$ is the Fisher $F$ parameter.

This correlation indicates that both set of values are equivalent, since by Student's t-test at $95 \%$ confidence level, the slope is not significantly different from 1 and the intercept

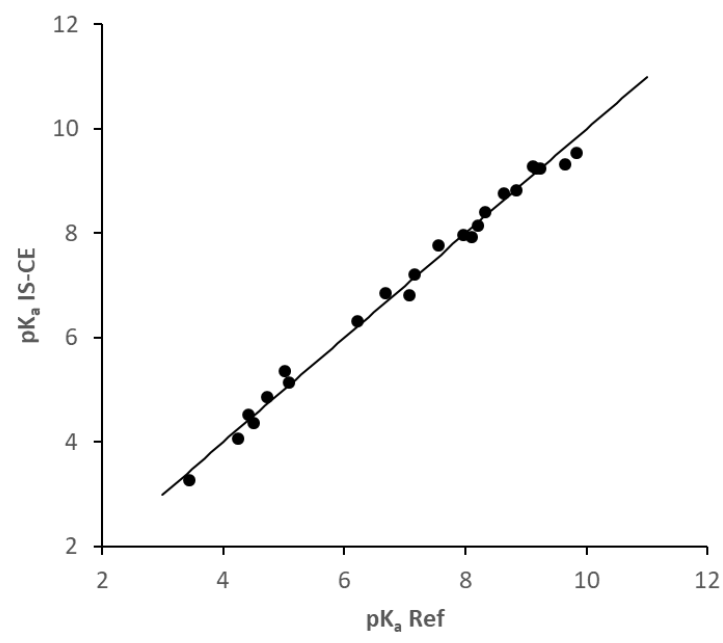

Fig. $1 \mathrm{pK}_{\mathrm{a}}$ values at $37^{\circ} \mathrm{C}$ obtained through the IS-CE method vs. the reference potentiometric ones. Solid line has an ordinate of 0 and a slope of 1. 
from 0 . Thus, the $\mathrm{pK}_{\mathrm{a}}$ values obtained follow a variation of acidity close to the reference one (slope one) and show a similar accuracy (intercept zero). However, for a best anchoring of the CE data to the potentiometric $\mathrm{pK}_{\mathrm{a}}$ scale, the differences between IS-CE and reference values have been

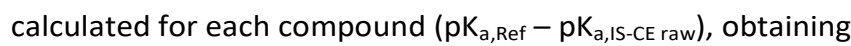
an average difference of -0.063 units (which would correspond to the intercept of the line of slope one). Then, the electrophoretic data has been corrected by this value to obtain the final values presented in Table 1 . The correlation between the IS-CE measured and reference potentiometric values is presented in Figure 1. This set of final $\mathrm{pK}_{\mathrm{a}}$ values can be used for determination of the $\mathrm{pK}_{\mathrm{a}}$ at $37 \stackrel{\mathrm{o}}{\mathrm{C}}$ of new compounds through the IS-CE method.

\section{Determination of $\mathrm{pK}_{\mathrm{a}}$ at $37{ }^{\circ} \mathrm{C}$ of polyprotic drugs through the IS- CE method.}

The method has been applied to the determination of acidity constants of seven polyprotic drugs. The selected drugs are of different nature and show a wide range of acid-base functionalities. Their structures are plotted in Figure 2. Although these molecules show multiple acid-base groups, only those $\mathrm{pK}_{\mathrm{a}}$ values ranging between 2 and 11 can be determined through electrophoretic methods.

In order to apply the IS-CE method, a first estimation of the $\mathrm{pK}_{\mathrm{a}}$ values of the drugs is needed. This can be easily done through estimation software, such as ACD/Percepta. ${ }^{36}$ This information allows the selection of the most appropriate standards (those Then, mixtures of the drug with each of the standards have been done, and electrophoretic runs performed. Effective mobilities have been measured at least in three different buffers (normally differing in $0.5 \mathrm{pH}$ units) for each druginternal standard pair. Additionally, actual ionic mobilities of the internal standards have also been determined to calculate the real $\mathrm{pH}$ value inside the capillary. When possible, actual ionic mobilities of the pure species of drug compounds have been measured too. To decide whether actual ionic mobilities of the drugs could be experimentally determined, the estimated $\mathrm{pK}_{\mathrm{a}}$ values at $25 \circ \mathrm{O}$ were used. In case that two consecutive $\mathrm{pK}_{\mathrm{a}} \mathrm{s}$ were separated enough (for instance the case of procainamide) or the $\mathrm{pK}_{\mathrm{a}}$ of the most charged species was not at very extreme $\mathrm{pH}$ values (like cephalexin) the experimental determination of the actual ionic mobilities was done. Otherwise, they have been calculated in the fitting process. Once the real $\mathrm{pH}$ inside the capillary is known, the mobility vs. $\mathrm{pH}$ curve for the drugs can be plotted. Equation 6 is then fitted to experimental points in order to obtain the $\mathrm{pK}_{\mathrm{a}}$ values. Figure 2 shows the different curves, and Table 2 the results obtained for the selected drugs together with the statistics of the fits ( $R^{2}$ is the determination coefficient, SD the standard error of the fit, and $\mathrm{F}$ the Fisher $\mathrm{F}$ parameter). $\mathrm{pK}_{\mathrm{a}}$ values have been corrected using the Debye-Hückel equation (eq. 5) for $50 \mathrm{mM}$ ionic strength, so that values given correspond to thermodynamic quantities.

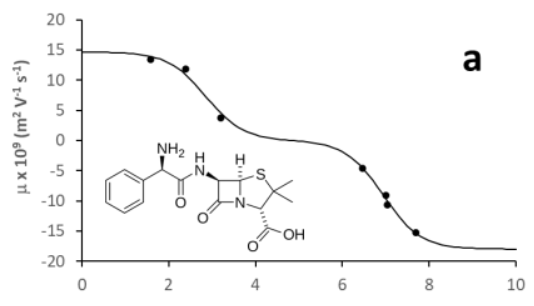

$\mathrm{pH}$
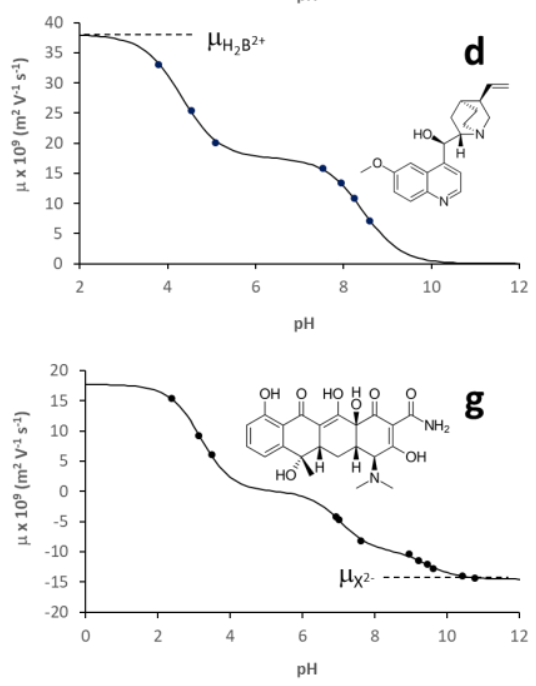

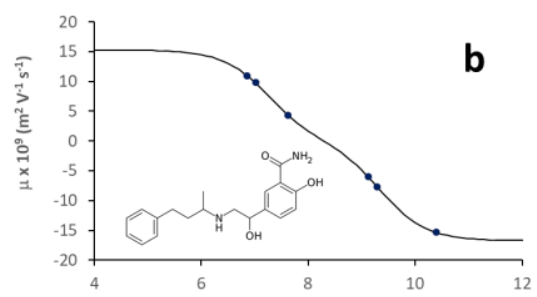

$\mathrm{pH}$
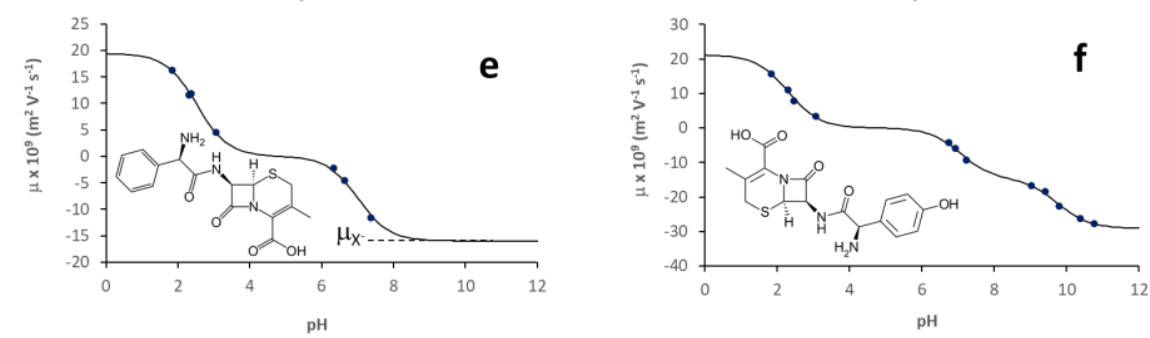

C

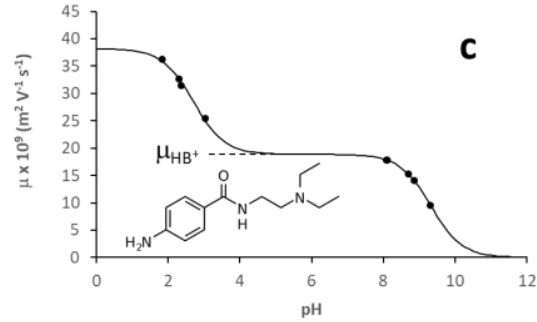

f

2 Mobility vs. pH profiles of the polyprotic drugs. Dots indicate the experimental points and the curves the fit of Eq. 6 to experimental data. Dashed lines indicate the experimentally measured mobilities. (a) ampicillin; (b) labetalol; (c) procainamide; (d) quinine; (e) cephalexin; (f) cefadroxil; (g) tetracycline. 
Table $2 \mathrm{pK}_{\mathrm{a}}$ values at $37{ }^{\circ} \mathrm{C}$ for the polyprotic drugs determined through the IS-CE method. Standard deviation is shown in parentheses.

\begin{tabular}{|c|c|c|c|c|c|c|c|}
\hline \multirow[t]{2}{*}{ Drug } & \multirow[t]{2}{*}{ Acid-base group } & \multirow[t]{2}{*}{$\mathrm{pK}_{\mathrm{a}}$} & \multirow[t]{2}{*}{$\mu_{\text {ion }} \times 10^{9}$ a } & \multirow[t]{2}{*}{$z^{b}$} & \multicolumn{3}{|c|}{ Statistics of the fit } \\
\hline & & & & & $R^{2}$ & SD & $\mathrm{F}$ \\
\hline \multirow[t]{2}{*}{ Ampicillin } & A (carboxylic acid) & $2.9(0.1)$ & $15(1)$ & +1 & 0.9969 & 0.90 & 318 \\
\hline & B (prim. amine) & $6.9(0.1)$ & $-18(2)$ & -1 & & & \\
\hline \multirow[t]{2}{*}{ Labetalol } & A (phenol) & $7.26(0.03)$ & $15.3(0.4)$ & +1 & 0.9999 & 0.14 & 9980 \\
\hline & B (second. amine) & $9.35(0.01)$ & $-16.7(0.2)$ & -1 & & & \\
\hline \multirow[t]{2}{*}{ Procainamide } & B (aniline) & $2.70(0.05)$ & $38.2(0.6)$ & +2 & 0.9987 & 0.38 & 2415 \\
\hline & B (tert. amine) & $9.33(0.02)$ & $18.9^{\mathrm{c}}$ & +1 & & & \\
\hline \multirow[t]{2}{*}{ Quinine } & B (heterocycle) & $4.31(0.03)$ & $38.0^{c}$ & +2 & 0.9992 & 0.30 & 2634 \\
\hline & B (second. amine) & $8.44(0.03)$ & $17.5(0.3)$ & +1 & & & \\
\hline \multirow[t]{2}{*}{ Cefalexin } & A (carboxylic acid) & $2.53(0.06)$ & $19.4(0.9)$ & +1 & 0.9985 & 0.49 & 1305 \\
\hline & B (prim. amine) & $7.01(0.04)$ & $-16.0^{c}$ & -1 & & & \\
\hline \multirow[t]{3}{*}{ Cefadroxil } & A (carboxylic acid) & $2.30(0.08)$ & $21(2)$ & +1 & 0.9990 & 0.63 & 1236 \\
\hline & B (prim. amine) & $7.07(0.08)$ & $-15(1)$ & -1 & & & \\
\hline & A (phenol) & $9.8(0.2)$ & $-29.1(0.9)$ & -2 & & & \\
\hline \multirow[t]{3}{*}{ Tetracycline } & A (phenol) & $3.19(0.03)$ & $17.7(0.4)$ & +1 & 0.9996 & 0.25 & 4344 \\
\hline & A (phenol) & $7.03(0.05)$ & $-9.8(0.4)$ & -1 & & & \\
\hline & B (tert. amine) & $9.5(0.1)$ & $-14.6^{c}$ & -2 & & & \\
\hline
\end{tabular}

a actual ionic mobility, in $\mathrm{m}^{2} \cdot \mathrm{V}^{-1} \cdot \mathrm{s}^{-1}{ }^{\mathrm{b}}$ charge number of the protonated or dissociated forms of the drug; ${ }^{\mathrm{c}}$ directly measured

Electrophoretic data of the determinations is presented in Tables SI-1 to SI-7 of the supplementary information.

Two different $\mathrm{pK}_{\mathrm{a}}$ values could be determined for all compounds, and three in case of cefadroxil and tetracycline. Statistical analysis shows that the fits of equation 6 to experimental data have coefficient of determination close to 1 , and in general, low standard deviations associated with the $\mathrm{pK}_{\mathrm{a}}$ values. However, this is usual in fits with a limited number of experimental points, especially if the actual ionic mobilities are also estimated. The highest standard deviation value corresponds to the third $\mathrm{pK}_{\mathrm{a}}$ of cefadroxil and is caused by the small variation of mobility with $\mathrm{pH}$ when changing from the monocharged to the dicharged negative species of cefadroxil. In the Table 2 are also indicated the acid-base groups associated to the $\mathrm{pK}_{\mathrm{a}}$ value. In the studied $\mathrm{pH}$ range procainamide and quinine are diprotic bases. Ampicillin, labetalol and cefalexin behave as zwitterionic compounds. Note that the only difference between cefalexin and cefadroxil is an extra phenolic group in cefadroxil $\left(\mathrm{pK}_{\mathrm{a} 3}\right)$. There is very good agreement between the $\mathrm{pK}_{\mathrm{a} 1}$ and $\mathrm{pK}_{\mathrm{a} 2}$ of both compounds, which correspond to identical acid-base moieties. Finally, tetracycline is a polyprotic compound with many acidbase groups. According to our data, it behaves as a triprotic compound in the $\mathrm{pH}$ range studied. A tentative assignation of the $\mathrm{pK}_{\mathrm{a}}$ values according to $\mathrm{ACD} /$ Percepta software indicates that the first $\mathrm{pK}_{\mathrm{a}}$ would belong to the phenolic group located in the amide ring, the second $\mathrm{pK}_{\mathrm{a}}$ to the phenolic group located in the following aromatic ring, and the third $\mathrm{pK}_{\mathrm{a}}$, in the basic $\mathrm{pH}$ region, would belong to the tertiary amine.

As commented in the previous section, there is relatively few data related to $\mathrm{pK}_{\mathrm{a}}$ values of drugs, especially polyprotic ones, determined at $37 \stackrel{\circ}{ } \mathrm{C}$. From the seven drugs studied in this work we could only find the $\mathrm{pK}_{\mathrm{a}}$ values of labetalol for comparison. They were determined potentiometrically by Avdeef et al. ${ }^{32}$ in a $0.2 \mathrm{M}$ ionic strength media, and their values are $7.25 \pm 0.01$ and $9.00 \pm 0.01$. In order to compare our 
results to the ones obtained in the literature, we have corrected the values from Avdeef et al. by the activity coefficients, obtaining $\mathrm{pK}_{\mathrm{a}}$ values of 7.25 and 9.28 , totally in accordance with the values obtained through the IS-CE method.

\section{Conclusions}

This work provides a set of internal standards for the high throughput determination of $\mathrm{pK}_{\mathrm{a}}$ values of drugs at the biorelevant temperature of 37 으. The IS-CE method has several advantages over other methods of $\mathrm{pK}_{\mathrm{a}}$ determination, but in this case it is of especial relevance that external measurement of the exact $\mathrm{pH}$ of the electrophoretic buffers and the $\mathrm{pH}$ electrode calibration at 37 으 can be avoided. Accurate results can be obtained with only few electrophoretic runs. Comparison of the $\mathrm{pK}_{\mathrm{a}}$ values at $25{ }^{\circ} \mathrm{C}$ to the ones at 37 oC for the set of internal standards indicates that in general $\mathrm{pK}_{\mathrm{a}}$ decreases when temperature increase, although the magnitude of the change does not follow a general trend, but depends on the nature of the compound evaluated. The method has been applied successfully to the determination of $\mathrm{pK}_{\mathrm{a}}$ values of polyprotic drugs, and very good accordance with available reference data has been observed.

\section{Conflicts of interest}

The authors declare no conflicts of interest.

\section{Acknowledgements}

Financial support from the Spanish Ministerio de Economía y Competitividad (CTQ2017-88179-P) and the Catalan Governments (2017SGR1074) is acknowledged.

\section{References}

1 Y. Henchoz, B. Bard, D. Guillarme, P. A. Carrupt, J. L. Veuthey and S. Martel, Anal. Bioanal. Chem., 2009, 394, 707-729.

2 D. T. Manallack, R. J. Prankerd, E. Yuriev, T. I. Oprea and D. K. Chalmers, Chem. Soc. Rev., 2013, 42, 485-496.

3 H. Wan, A. Holmén, M. Någård and W. Lindberg, J. Chromatogr. A, 2002, 979, 369-377.

4 D. E. Francke and H. A. K. Whitney Jr., Perspectives in Clinical Pharmacy, Drug Intelligence Publications, Hamilton, 1972.

5 N. Sun and A. Avdeef, Pharm. Biomed. Anal., 2011, 56, 173-182.

6 R. S. Gravador, E. Fuguet, C. Ràfols and M. Rosés, Electrophoresis, 2013, 24, 1203-1211.

7 W. H. Streng and D. L. Steward Jr., Int. J. Pharm., 1990, 61, 265-266.

8 R. J. Prankerd, Profiles Drug Subst. Excip. Relat. Methodol., 2007, 33, 1-33.
9 L. Eberson, Acidity and hydrogen bonding of carboxyl groups, in: S. Patai (Ed.), The chemistry of carboxylic acids and esters, Interscience Publishers, New York, 1969, pp. 211-293.

10 D. D. Perrin, Aust. J. Chem., 1964, 17, 484-488.

11 G. Völgyi, E. Baka, K. Box, J. Comer and K. Takáks-Novák, Anal. Chim. Acta, 2010, 673, 40-46.

12 J. Reijenga, A. van Hoof, A. van Loon and B. Teunissen, Anal. Chem. Insights, 2013, 8, 53-71.

13 S. J. Gluck, K. P. Steele and M. H. Benkö, J. Chromatogr. A, 1996, 745, 117-125.

14 E. Fuguet, M. Reta, C. Gibert, M. Rosés, E. Bosch and C. Ràfols, Electrophoresis, 2008, 29, 2841-2851.

15 P. Nowak, M. Wozniakiewicz and P. Koscielniak, J. Chromatogr. A, 2015, 1377, 1-12.

16 D. Geffertova, S. T. Ali, V. Solinova, M. Krecmerova, A. Holy, Z. Havlas and V. Kasicka, J. Chromatogr. A, 2017, 1479, 185193.

17 M. Wozniakiewicz, P. M. Nowak, M. Golab, P. Adamowicz, M. Kala and P. Koscielniak, Talanta, 2018, 180, 193-198.

18 M. Maly, M. Boublik, M. Pocrnic, M. Ansorge, K. Lorincikova, J. Svobodova, V. Hruska, P. Dubsky and B. Gas, Electrophoresis, 2020, 41, 493-501.

19 S. K. Poole, S. Patel, K. Dehring, H. Workman and C. F. Poole, J. Chromatogr. A, 2004, 1037, 445-454.

20 E. Fuguet, C. Ràfols, E. Bosch and M. Rosés, J. Chromatogr. A, 2009, 1216, 3646-3651.

21 J. M. Cabot, E. Fuguet and M. Rosés, ACS Comb. Sci., 2014, 16, 518-525.

22 J. M. Cabot, E. Fuguet, C. Ràfols and M. Rosés, J. Chromatogr. A, 2010, 1217, 8340-8345.

23 D. Koval, V. Kasicka, J. Jiracek, M. Collinsova and T. A. Garrow, J. Chromatogr. B, 2002, 770, 145-154.

24 K. Vcelakova, I. Zuskova, E. Kenndler and B. Gas, Electrophoresis, 2004, 25, 309-317.

25 D. Koval, V. Kasicka, J. Jiracek, M. Collinsova and T. A. Garrow, Electrophoresis, 2002, 23, 215-222.

26 P. M. Nowak, M. Wozniakiewicz, M. Mitoraj, F. Sagan and P. Koscielniak, J. Chromatogr. A, 2018, 1539, 78-86.

27 E. Fuguet, C. Ràfols and M. Rosés, J. Chromatogr. A, 2011, 1218, 3928-3934.

28 R. P. Schwarzenbach, P. M. Gschwend and D. M. Imboden, Environmental Organic Chemistry, second edition, John Wiley \& Sons, Inc., Medford, 2003.

29 M. Meloun, S. Bordovská and L. Galla, J. Pharm. Biomed. Anal., 2007, 45, 552-564.

30 A. Albert and E. P. Serjean, The determination of ionization constants - A laboratory manual, second edition, Chapman and Hall, London, 1971.

31 D. Perrin, Dissociation constants of organic acids in aqueous solution, International union of pure and applied chemistry, Butterworths, London, 1965.

32 A. Avdeef and O. Tsinman, Pharm. Res., 2008, 25, 26132627.

33 G. R. Strichartz, V. Sanchez, G. R. Arthur, R. Chafetz, and D. Martin, Anesth. Analg., 1990, 71, 158-170. 
Journal Name

34 A. Avdeef and N. Sun, Pharm. Res., 2011, 28, 517-530.

35 M. Meloun, T. Syrov and A. Vrana, Anal. Chim. Acta, 2005, 533, 97-110.

36 ACD/Percepta, www.acdlabs.com, Advanced Chemistry Development, Inc., Release (Build 2726, 5359 May 2014). 